\title{
Experimental Study of Human Behavior in Smoke Filled Corridors
}

\author{
TADAHISA JIN and TOKIYOSHI YAMADA \\ Fire Research Institute \\ Fire Defense Agency \\ Ministry of Home Affairs \\ 3-14-1 Nakahara, Mitaka-shi \\ Tokyo 181, Japan
}

ABSTRACT

An experimental study was conducted in order to clarify a degree of human emotional instability under smoke condition. Mental arithmetic and walking speed were adopted as indices of the emotional instability, and furthermore an annoyance of smoke and heat was investigated by questionnaire. The emotional instability caused by physiological factors, such as smoke irritation, is found to be important as well as a psychological unrest under high irritant smoke. Such fire smoke affects the thinking power and walking speed. Especially the heat from smoke is found to reduce the thinking power in the range between $2,030 \mathrm{kcal} / \mathrm{m}^{2} \mathrm{~h}$ and $1,370 \mathrm{kcal} / \mathrm{m}^{2} \mathrm{~h}$.

\section{INTRODUCTION}

A smoke obstruction against safety evacuation has been pointed out through many fires in the past. High level of carbon monoxide gas density and deficiency of oxygen in fire smoke are main physiological factors to decide life or death. However, physical and psychological effects of thinner smoke, a decrease of visibility through smoke and/or smoke irritation for instance, tend to panic the evacuees and indirectly lead to death.

Many experimental studies of such smoke effects have been conducted in our laboratory with the smoke of normal temperature. $[1,2,3,4]$ However in these experiments, hot smoke effects on a human emotional instability were not considered. Therefor an additional experiment was conducted to clarify complex effect of smoke and heat, using electric heat radiator.

Subjects were exposed to smoke environments in a corridor and in each experiment, the physiological and psychological effects of smoke and/or heat radiation were investigated with mental arithmetic, walking speed and questionnaire.

\section{METHOD AND CONDITION OF EXPERIMENT}

31 subjects participated in this experiment. The experiment was conducted in a smoke filled corridor. Wach subiect was asked to walk 


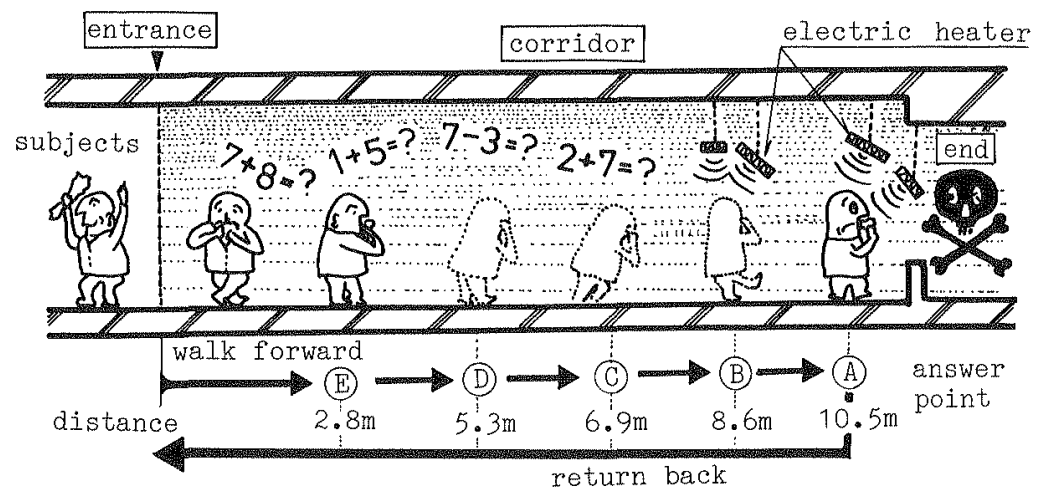

FIGURE 1. Outiine of experiment.

forward in this corridor while doing simple additional and subtractive calculations as shown in Fig. 1.

Experimental condition of the corridor

The experiment was conducted in a straight corridor of about $11 \mathrm{~m}$ depth, $2.5 \mathrm{~m}$ height, $1.2 \mathrm{~m}$ width. On its floor, five mats, in which an on-off switch was equipped, were set to indicate where the subject was to stand. At each of these five points, subjects were asked to answer arithmetic questions as mentioned later.

The corridor was filled with white smoke generated by smoldering Japanese cedar crib chips in an electric furnace before starting each experiment. At the beginning of the experiment, a smoke density expressed by the extinction coefficient was adjusted to $1.2 \mathrm{l} / \mathrm{m}$ and was weakened slowly to the $0.1 \mathrm{l} / \mathrm{m}$ during 30 minutes. In this 30 minutes duration, two or three subjects entered into the corridor individually under various kinds of smoke density conditions.

Temperature inside the corridor was about $20^{\circ} \mathrm{C}$. At the inner point of $A$ and $B$, the heat was radiated to subjects with an electric radiator (at $A->12 \mathrm{KW}, B \rightarrow 3 \mathrm{KW}$ ) installed at a ceiling. A maximum heat flux density was $2,030 \mathrm{Kcal} / \mathrm{m}^{2} \mathrm{~h}$ at A-point of $1.5 \mathrm{~m}$ height from the floor level and $1,370 \mathrm{Kcal} / \mathrm{m}^{2} \mathrm{~h}$ at $\mathrm{B}$-point of the same height. Mean Radiant Temperature measured with a glove thermometer was about $82^{\circ} \mathrm{C}$ at A-point and $75^{\circ} \mathrm{C}$ at $\mathrm{B}$-point.

The inside of the corridor was illuminated by fluorescent lamps, and the illumination on the floor level were in the range of $301 \mathrm{x}$ to $1001 x$. The walking speed between each answer point was estimated with mat switches as reference data represent the emotional instability.

\section{Mental arithmetic}

In this experiment, a mental arithmetic method was adopted to estimate the degree of emotional instability under smoke condition. The rate of correct answers to simple arithmetic questions was expected to 
decrease continuously with increasing the human emotional instability to a certain extent. This rate was therefore adopted as an index of the emotional instability.

The mental arithmetic questions were recorded in an endless tape and 10 questions were continuously addressed to the subject by a loud speaker at each five answer points (A to E). Three kinds of question interval speed, 1.5 sec./question for male and 2.0 to 2.5 sec./question for female, were selected to compensate for individual difference.

This set of 10 questions was repeatedly given with an interval of 10 sec. The subject was asked to answer the questions at each answer point. After answering the questions at one point, they were asked to move to the next deeper position during this $10 \mathrm{sec}$. interval. This action was repeatedly conducted to the deepest A-point. The answers were voice recorded in a handy type tape recorder and were rated after the experiment.

These data were normalized by an average correct rate of 90 questions under normal condition, without smoke and heat radiation, to compensate for individual differences of calculation ability.

Subjects

31 adults aged 20 to 51 (male 14, female 17) participated in this experiment. These females were mainly house wives and males were university students.

Before the experiment, no detailed information of the corridor were given and the corridor state without smoke was not displayed. The subjects were only told that this was an experiment concerning safety and were given fundamental instructions, i.e., "a corridor filled with smoke is strait and has an end and subjects are allowed to return back whenever they want to."

The subjects were protected from smoke irritation with a 16 layered towel on their mouth and nose. As proven in a previous experiment, this towel protected the subjects from $90 \%$ of the smoke.[5]

\section{RESULTS AND CONSIDERATIONS}

Interruption of experiment

At the beginning of each experiment, the condition of the smoke density was not the same. The values varied in the rage of $\mathrm{Cs}=0.92 \pm$ $0.21 \mathrm{1} / \mathrm{m}$. In first experiment trial with thicker smoke, 17 subjects (male 6, female 11) could reach the deepest A-point, and other 14 subjects (male 8, female 6) returned back with interruption.

Fig.2 shows a relation between an attainable distance and the correct answer rate of the latter 14 subjects. Seven subjects interrupted their walk at the nearest E-point ( $2.8 \mathrm{~m}$ from entrance) and the correct rate fell down to about $7 \%$ of the normal correct rate. Six. out of these seven subjects interrupted again in the second trial under 


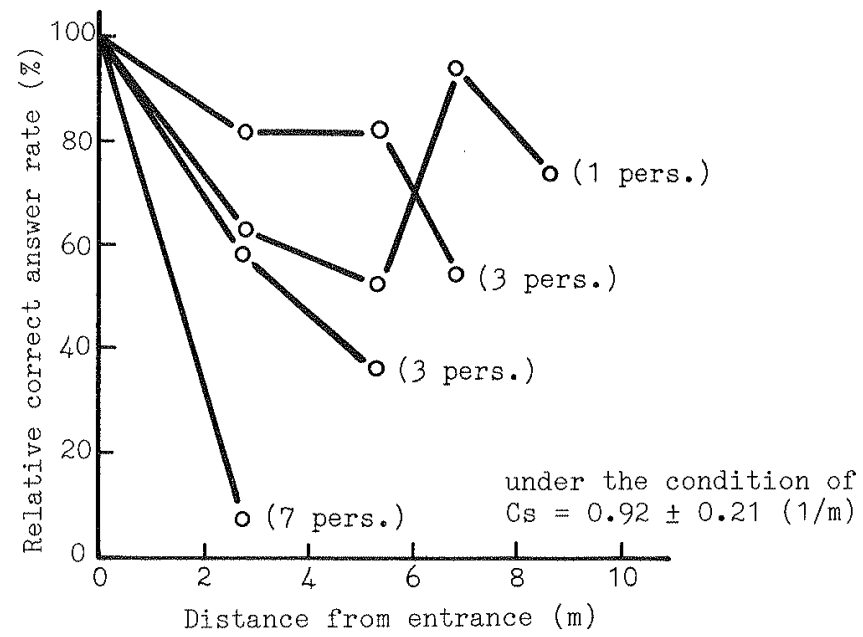

FIGURE 2. Relation between distance from entrance and correct answer rate: 14 subjects ( 8 males, 6 females) returned back with interruption.

condition of $\mathrm{Cs}_{\mathrm{s}}=0.66 \mathrm{I} / \mathrm{m}$, and moreover two of them did in the third trial (Cs $=0.62)$.

In the first trial under thick smoke, three subjects turned back at D-point ( $5.3 \mathrm{~m}$ distance from entrance), other three at $\mathrm{C}$-point $(6.9 \mathrm{~m})$, one at B-point $(8.6 \mathrm{~m})$, and the each correct answer rate was about $35 \%$, $55 \%$ and $75 \%$. The correct rate decreases when the subjects returned back earlier, that is, the emotional instability is larger when the subjects returned back earlier.

Correct answer rate and emotional instability

Some subjects were able to reach the end of the corridor in the first trial under thicker smoke. A solid line of Fig.3 shows the relation between the attainable distance from the entrance and the correct answer rate. This average rate of 17 subjects falls down at the lowest just after entering the corridor (at E-point) and it tends to rise up at deeper points.

However, in inquiries conducted after experiment, the subjects pointed out that they felt more unrest when they walked forward. Experimental results of walking speed as mentioned later support the validity of these indications. From these facts, the relative correct rate caused by psychological factors is considered to decrease under a certain conditions, which is unknown in this experiment, when subjects walk forward as shown in Fig.3 with long dashed line.

From the view point of physiological aspects, the abrubt decrease of correct rate just after entering the corridor can be explained by the smoke which attacks the subject's eyes and throat. As this discomfort is lightened with the lapse of time, the correct answer rate may rise when subjects walk forward as shown in Fig. 3 with dashed and dotted line. The heat radiation effect is involved at $A$ and $B$-point. 
The obtained experimental data as shown in Fig.3 with solid line appears to be composed of two kinds of smoke effect, the physiological and psychological effect on subjects. The relation between these two effects i.e., whether a simple algebra of addition can explain the data or not, is a task for further investigations.

Heat flux effect on correct answer rate

Fig. 4 presents the mental arithmetic results under no smoke condition. The data at A-point drop to $10 \%$ lower than those of other points. This decrease is caused by the heat radiation from an electric heat radiator installed at the ceiling. The same drop at A-point is also apparently recognized under smoke condition presented with normal line in Fig.3. Nevertheless, no fall is found at B-point.

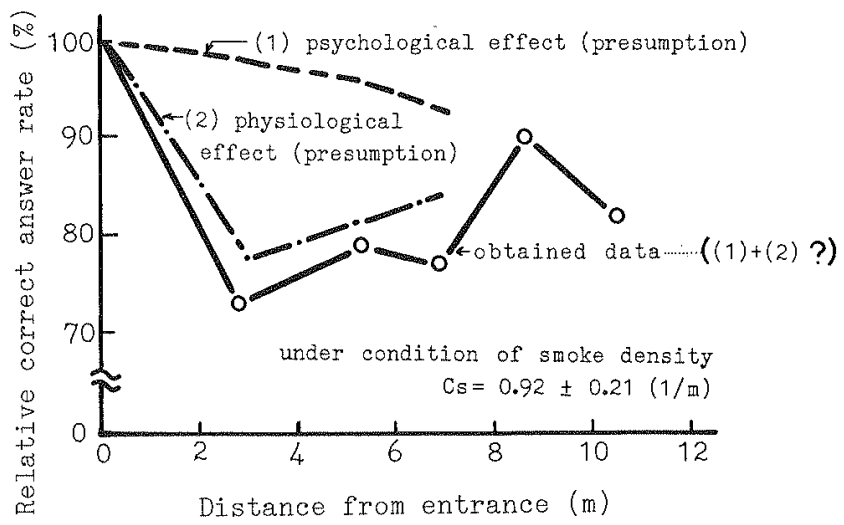

FIGURE 3. Relation between distance from entrance and correct answer rate: 17 subjects $(6$ males, 11 females) reached at the end of corridor in first trial.

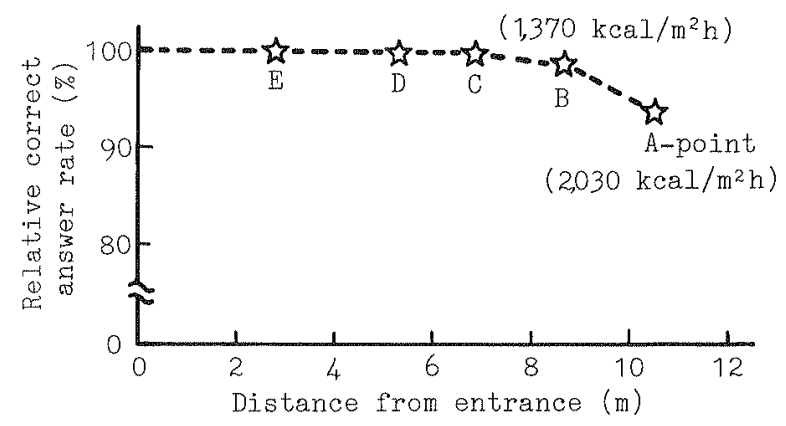

FIGURE 4. Relation between distance from entrance and correct answer rate with electric heater and without smoke: the electic heater is installed at $\mathrm{A}$ and $\mathrm{B}$-point. 


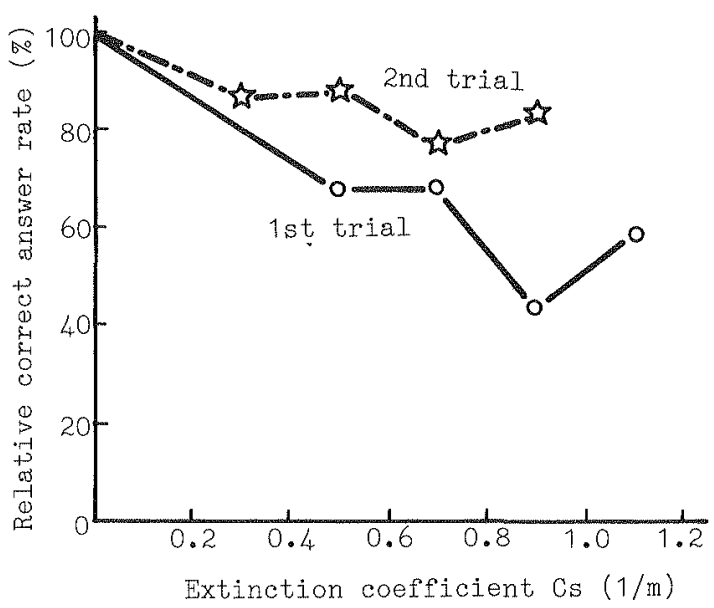

FIGURE 5. Relation between smoke extinction coefficient and correct answer rate: at the E-point and in the first and second trial.

The maximum heat flux intensity was $2,030 \mathrm{Kcal} / \mathrm{m}^{2} \mathrm{~h}$ at $1.5 \mathrm{~m}$ height rom the floor of A-point and $1,370 \mathrm{Kcal} / \mathrm{m}^{2} \mathrm{~h}$ at B-point. So the threshold value of heat flux reduces human thinking power is in the range of between $2,030 \mathrm{Kcal} / \mathrm{m}^{2} \mathrm{~h}$ and $1,370 \mathrm{Kcal} / \mathrm{m}^{2} \mathrm{~h}$.

Smoke density effect on correct answer rate

Fig.5 shows the relation between smoke density and correct answer rate. It indicates that the correct rate decreases with increasing the smoke density almost linearly. This corelation agrees with the other experimental results.[3]

The adaptability of humans to smoke environment is recognized in this figure clearly. The dashed and dotted line shows the second trial result of the same subject. The correct rates get about $30 \%$ better than those of the first trial. It is concluded that the assimilation effect depends on the number of experiment trial and an exposed time duration in smoke condition.

Walking speed in fire smoke

The walking speed between each point was measured in this experiment. Fig.6 and Fig.7 show the results. The walking speed decreases in proportion to the distance from the entrance as shown in Fig.6. The variance between male and female walking speed is not distinctive in thin smoke, however the declining rate of female walking speed is higher in thick smoke.

The smoke effect on the walking speed is shown in Fig.7. The results are almost the same as the correct answer rate, that is, the walking speed decreases with increasing smoke density. The decrement of the walking speed is lower than the other former experimental results.[1] This may be caused by the differences in experimenta] 


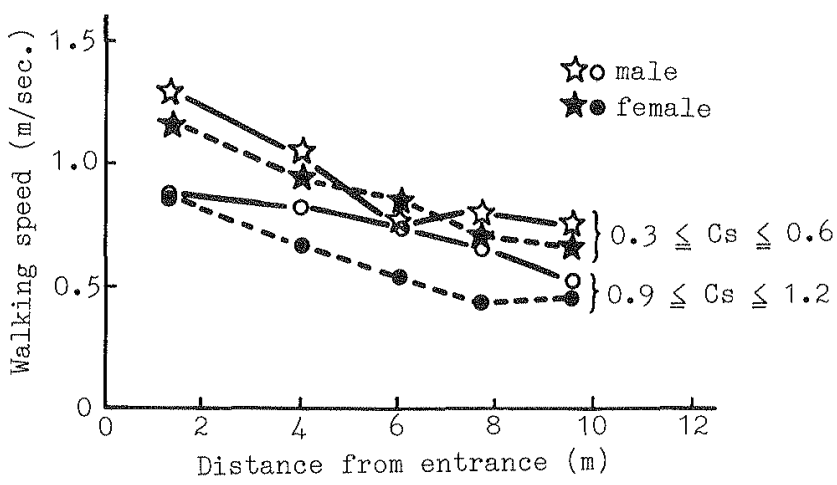

FIGURE 6. Relation between distance from entrance and walking speed.

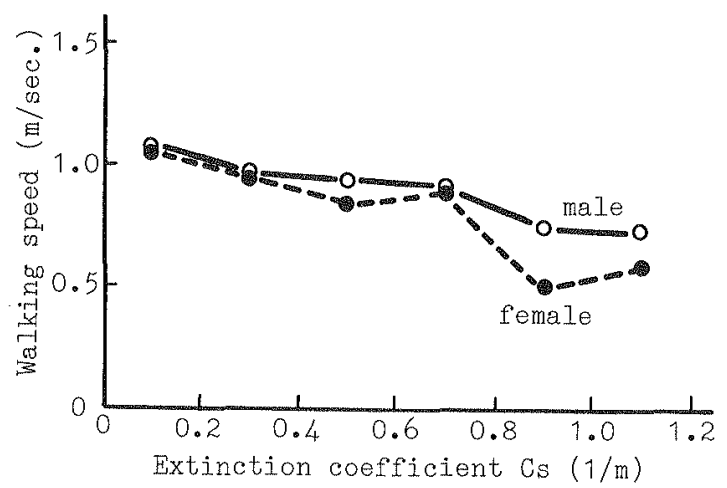

FIGURE 7." Relation between smoke extinction coefficient and walking speed.

conditions and methods. The use of a towel to protect fire smoke in this experiment seems to be the main reason. About $90 \%$ of smoke are removed with this towel and it lessens the smoke irritation effect.

\section{INQUIRY RESULTS}

Some questions were asked to each subject after the experiment. One was a question on uncomfortable factors of smoke: "What are the uncomfortable factors of smoke? Select three factors concerned with fire smoke from following items in order !"

Tab.1 shows the result. Some variances between male and female are found. Physiological factors were mainly selected by males. Eyes and/or throat irritation was the first or second selected item. "Obstruction of inhalation" was selected as the second or the third uncomfortable factor. 
In comparison with the above males' answers, females tended to feel psychological discomfort. The obstruction of visibility was selected as the first cause of discomfort of females along with an irritation and inhalation problem. This obstruction of visibility was also cited as the second cause. This experimental result indicates that the emotional instability in thick fire smoke is not necessarily caused by the same factors for males and females. Under thin smoke conditions, the smoke irritation and heat flux are selected as the first or the second factor without distinction of sex.

Tab.2 indicates the results of the inquiry regarding emotional reactions towards radiant heat flux. At B-point, the power of electric heat radiator (about $3 \mathrm{KW}$ ) is too small to raise the subject's discomfort. The answer was mainly "just feel heat a little", the other point (A-point with $12 \mathrm{Kw}$ heater), $44 \%$ of subjects answered "hot but not intolerablell under smoke condition, however this rate increased to $50 \%$ under no smoke condition. $7 \%$ of subjects answered "intolerably hot" under smoke condition, and $29 \%$ under no smoke condition.

In this experiment, the intensity of heat flux on subjects were almost the same under thin and thick smoke conditions. The surrounding smoke may psychologically blunt the feeling on heat flux.

TABLE 1. Uncomfortable factor of fire smoke: Question "Select three factors concerned with fire smoke from following items !"

\begin{tabular}{|c|c|c|c|c|c|c|c|}
\hline \multirow{2}{*}{\multicolumn{2}{|c|}{ selection items }} & \multicolumn{3}{|c|}{$\operatorname{male}(\%)$} & \multicolumn{3}{|c|}{ female (\%) } \\
\hline & & $1 \mathrm{st}$ & 2nd & $3 \mathrm{rd}$ & $1 \mathrm{st}$ & 2nd & $3 \mathrm{rd}$ \\
\hline 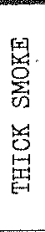 & $\begin{array}{l}\text { a. foul smell } \\
\text { b. smoke irritation } \\
\text { c. obstruction of inhalaion } \\
\text { d. obstruction of visibility } \\
\text { e. heat } \\
\text { f. feeling of isolation } \\
\text { g. others }\end{array}$ & $\begin{array}{l}1(7 \%) \\
8(57 \%) \\
5(36 \%) \\
0(0 \%) \\
0(0 \%) \\
0(0 \%) \\
0(0 \%)\end{array}$ & $\begin{array}{l}2(14 \%) \\
4(29 \%) \\
4(29 \%) \\
3(21 \%) \\
1(7 \%) \\
0(0 \%) \\
0(0 \%)\end{array}$ & $\begin{array}{l}3(21 \%) \\
1(7 \%) \\
5(36 \%) \\
3(21 \%) \\
0(0 \%) \\
1(7 \%) \\
1(7 \%)\end{array}$ & $\begin{array}{l}1(6 \%) \\
7(41 \%) \\
4(24 \%) \\
5(29 \%) \\
0(0 \%) \\
0(0 \%) \\
0(0 \%)\end{array}$ & $\begin{array}{l}0(0 \%) \\
6(35 \%) \\
3(18 \%) \\
6(35 \%) \\
1(6 \%) \\
1(6 \%) \\
0(0 \%)\end{array}$ & $\begin{array}{l}1(7 \%) \\
2(13 \%) \\
6(40 \%) \\
5(33 \%) \\
0(0 \%) \\
1(7 \%) \\
0(0 \%)\end{array}$ \\
\hline 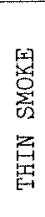 & $\begin{array}{l}\text { a. foul smell } \\
\text { b. smoke irritation } \\
\text { c. obstruction of inhalaion } \\
\text { d. obstruction of visibility } \\
\text { e. heat } \\
\text { f. feeling of isolation } \\
\text { g. others }\end{array}$ & $\begin{array}{l}2(14 \%) \\
6(43 \%) \\
3(21 \%) \\
0(0 \%) \\
3(21 \%) \\
0(0 \%) \\
0(0 \%)\end{array}$ & $\begin{array}{l}2(17 \%) \\
0(0 \%) \\
3(25 \%) \\
1(8 \%) \\
5(42 \%) \\
0(0 \%) \\
1(8 \%)\end{array}$ & $\begin{array}{l}3(30 \%) \\
2(20 \%) \\
4(40 \%) \\
0(0 \%) \\
1(10 \%) \\
0(0 \%) \\
0(0 \%)\end{array}$ & $\begin{array}{l}2(13 \%) \\
3(19 \%) \\
2(13 \%) \\
0(0 \%) \\
8(50 \%) \\
1(6 \%) \\
0(0 \%)\end{array}$ & $\begin{array}{l}7(50 \%) \\
4(29 \%) \\
1(7 \%) \\
0(0 \%) \\
0(0 \%) \\
2(14 \%) \\
0(0 \%)\end{array}$ & $\begin{array}{l}2(15 \%) \\
2(15 \%) \\
3(23 \%) \\
1(8 \%) \\
2(15 \%) \\
2(15 \%) \\
1(8 \%)\end{array}$ \\
\hline
\end{tabular}

TABLE 2. Feeling for heat radiation under smoke and no smoke condition: Question "How do you feel for the heat flux on you at the deepest $A$ point ?"

\begin{tabular}{|c|c|c|c|c|}
\hline selected items & with & smoke & without & smoke \\
\hline 1. intolerably hot & 2 & $(7 \%)$ & 8 & $(29 \%)$ \\
\hline 2. hot but not intolerable & 13 & $(44 \%)$ & 14 & $(50 \%)$ \\
\hline 3. comfortably warm & 7 & $(23 \%)$ & 4 & $(14 \%)$ \\
\hline 4. just feel heat a little & 4 & $(13 \%)$ & 2 & $(7 \%)$ \\
\hline 5. no feeling & 4 & $(13 \%)$ & 0 & $(0 \%)$ \\
\hline
\end{tabular}




\section{CONCLUSION}

The following results were obtained on the emotional instability affected by smoke from this experiment.

1. The emotional instability in fire smoke is caused by psychological and physiological factors. However a quantitative analysis on the ratio of each factor was not clarified in this experiment. time.

2. The degree of fire smoke annoyance decreases with the lapse of

3. The walking speed in fire smoke decreases with increased smoke density and walking distance from the entrance in the corridor.

4. The emotional instability affected by smoke was found to be different between males and females qualitatively. Whereas males tended to feel physiological discomfort, the psychological factors including the decrease of visibility are dominant for females.

5. The threshold of the heat flux affects the thinking ability is in the range between $2,030 \mathrm{kcal} / \mathrm{m}^{2} \mathrm{~h}$ and $1,370 \mathrm{kcal} / \mathrm{m}^{2} \mathrm{~h}$.

\section{REFERENCES}

1. T.Jin, Visibility through fire smoke, J.Fire \& Flammability, 9: pp.135-157, April 1978.

2. T.Jin, Studies of emotional instability in smoke from fires, J.Fire \& Flammability, 12: pp.130-142, April 1981.

3. T.Jin, Studies on decrease of thinking power and memory in fire smoke, Bull. of Japanese Assoc. of Fire Science \& Eng.,32: 2, pp.43-47, 1982.

4. T.Jin, T.Yamada, Irritating effects of fire smoke on visibility, Fire Science \& Technology, 5: 1, p.79-89, 1985.

5. T.Jin, Effect of smoke reduction with a wet towel, Bull. of Japanese Assoc. of Fire Sci. \& Eng., 31: 5, p.26-30, 1981. 